\title{
Morphological Progression of Chorionic Membrane Development in Monochorionic and Dichorionic Twins: A Sonographic Assessment
}

\section{Airat Adeola Bakare ${ }^{1 *}$, Afodun Adam Moyosore ${ }^{2,3}$, Eze Daniel Ejike4, Adesanya Olamide Adewale ${ }^{2}$, Edgar Mario Fernandez ${ }^{2}$, Quadri Khadijah Kofoworola ${ }^{5}$, Ilugbo Kehinde Hussein ${ }^{6}$}

\author{
${ }^{1}$ Department of Anatomy, College of Medicine, University of Lagos, Idi-Araba, Lagos, Nigeria \\ ${ }^{2}$ Department of Anatomy, Faculty of Biomedical Sciences, Kampala International University, Kampala, Uganda \\ ${ }^{3}$ Department of Radiology, Ultrasound and Doppler Unit, Crystal Specialist Hospital, Akowonjo-Dopemu, Lagos \\ ${ }^{4}$ Department of Physiology, Faculty of Biomedical Sciences, Kampala International University, Kampala, Uganda \\ ${ }^{5}$ Department of Physiology, College of Medicine, University of Lagos, Idi-Araba, Lagos, Nigeria \\ ${ }^{6}$ Department of Internal Medicine, Faculty of Clinical Sciences, University of Ilorin, Ilorin, Kwara State, Nigeria \\ Email: *afodunadam@yahoo.com
}

\begin{abstract}
How to cite this paper: Bakare, A.A., Moyosore, A.A., Ejike, E.D., Adewale, A.O., Fernandez, E.M., Kofoworola, Q.K. and Hussein, I.K. (2018) Morphological Progression of Chorionic Membrane Development in Monochorionic and Dichorionic Twins: A Sonographic Assessment. Open Journal of Obstetrics and Gynecology, 8, 1596-1603.
\end{abstract}

https://doi.org/10.4236/ojog.2018.814160

Received: November 6, 2018

Accepted: December 25, 2018

Published: December 28, 2018

Copyright ( 92018 by authors and Scientific Research Publishing Inc. This work is licensed under the Creative Commons Attribution International License (CC BY 4.0).

http://creativecommons.org/licenses/by/4.0/

(c) (i) Open Access

\begin{abstract}
Background: The zygote of twins implants themselves separately and on different spots in the uterine endometrium. However, the growth of fetal membranes may be collective or singly. There is little data from sonographic view of assessment on the exact progression at different stages of gestation. More so, the realistic evidences from radiographic assessment of the compartmentalization of chorion membrane in the developing monochorionic and dichorionic twins are not sufficiently available, hence, the call to ascertain the exact progression of the chorion membrane through ultrasound scanning in gestational subjects. Aim: This present study examined the structural progression of embryonic growth pattern of chorionic membrane in monochorionic and dichorionic twins. Materials and Methods: The study utilized transabdominal ultrasound to periodically assess the progression of chorion membrane and advancement in compartmentalization of monochorionic and dichorionic twins as pregnancy proceeds. Results: The monochorionic membrane showed an enclosure that progresses to be more distinct and thickened around the two embryos with a unique $\mathrm{T}$-shaped point of insertion in latter development. The partitioning of dichorionic membrane progresses to be less thickened and with a distinct lambda $(\lambda)$ sign which is a wedge-shaped protrusion into the inter-twin space. Conclusion: Assessment showed that the growth pattern of chorion membrane varied with different parameters observed as early as in the first trimester. Hence during early gestational stage, a twin can be said to be monochorionic or dichorionic with key anatomical
\end{abstract}


landmarks monitored. The growth progression could be used to project abnormality and on time treatment would be offered to improve perinatal outcome.

\section{Keywords}

Chorionic Membrane, Twin, Progression, Gestation, Ultrasound

\section{Introduction}

Twins are the most frequent form of multiple births in human. Twins can either be monozygotic, which are usually identical meaning that they develop from one zygote, which splits to form two embryos or dizygotic or fraternal meaning that they develop from two different eggs and fertilized by its own sperm cell. Whichever ways, the developing twin embryos implant themselves separately [1].

The chorion is a vascular tissue that generates during embryological development between the developing fetus and mother. The chorionic membrane undergoes rapid proliferation and forms numerous processes; the chorionic villi, which invade and destroy the uterine decidua and at the same time absorb nutritive materials for the growth of the embryo. The development of chorionic membranes could be individual as in dichorionic or collective as posed in monochorionic twins [2]. The monochorionic twins share the same chorionic sac or membrane. It occurs in $75 \%$ of monozygotic (identical) twins and $0.3 \%$ of all pregnancies [2] [3]. The dichorionic occurs when each twin has its own chorionic sacs. This type occurs most commonly with dizygotic twins, but may also occur with monozygotic twin pregnancies [3].

Congenital anomalies are 1.2 to 2 times more common in twin gestation than singletons, which is due to the relative risk outcome on whether each fetus attaches to its own embryonic membrane [4]. The management of some structural anomalies, identifying aneuploidy and early diagnosis of twin-to-twin transfusion syndrome depends largely on chorionicity. Early and accurate determination and progression of chorion membrane are critical in the antenatal management of twins as early and intensive monitoring and intervention may improve outcomes [5] [6] [7].

Additionally, the study of chorion membrane from developing embryo is routinely used in biological and biomedical research to investigate some developmental processes and malformation such as; angiogenesis and tumor metastasis [8] [9]. Thus, data of realistic evidence from sonographic view of assessment of the true progression of chorion membrane in monochorionic and dichorionic twins at various stages of gestation are few. Though a silent area of development, but of great clinical importance, critical to knowledge acquisition and discovery of abnormalities, it is therefore imperative to carry out this assessment to determine the progression of chorion membrane through ultrasound scanning in gestational subjects. This present study utilized sonographic representation that 
enabled the assessment of morphological progression of embryonic growth pattern of chorion membrane and its advancement in compartmentalizing the gestational sac as pregnancy proceeds.

\section{Subjects and Methods}

Sonographic assessment utilized female patients gravid with twins that visited the Ultrasound Unit of Crystal Specialist Hospital (CSH), Akowonjo-Dopemu, Lagos Nigeria, for routine gynecological and obstetrics evaluation of chorionic membrane from January to July, 2016. The women were asymptomatic and aged between 28 and 32 years. The evaluations were done in the $8^{\text {th }}$ (first trimester) and $25^{\text {th }}$ (second trimester) week of gestation as Crown-Rump Length (CRL) was used to ascertain embryonic age in the former. At the latter, Bi-parietal Diameter (BPD)/ Femoral Length (FL) biometry was employed. Reduced liquor volume towards term (39 weeks \pm 2 weeks) may obscure chorionic visibility at the point of membranous insertion. A total of six pregnant women were examined by trans-abdominal ultrasound (General Electric-Pro Logic 3; made in U.S.A), using a curvilinear transducer with $3.5 \mathrm{MHz}$ frequency. Data about parity showed 1 woman was nulliparous, 3 had 1 previous birth and 2 were multiparous. Body Mass Index (BMI) was average ranging from 19.51 to $24.02 \mathrm{~kg} / \mathrm{m}^{2}$. The uterus was visualized as a pear-shaped anteverted structure superior to the vagina and posterior to the urinary bladder. Exclusion criteria for women were; pregnancies with triplets, singletons, fetuses with malformations /apparent congenital anomalies, gravidae complicated by gestational diabetes mellitus, females below 28 years and above 32 years age bracket. The chorion membrane was identified ultrasonically as the thin partitioning membrane. The region of chorionic formation was critically focused, frozen and printed for morphological progression assessment.

\section{Informed Consent}

All procedures followed were in accordance with the ethical standards of the responsible committee on human experimentation (institutional and national) and with the Helsinki declaration of 1975, as revised in 2000. The patient provided written informed consent before enrolment into the study.

\section{Results}

A total of six female patients were scanned with twins. Two of which were carrying monochorionic twins while four were gravid with dichorionic fetuses. The best representation was taken and progression was studied. The chronic membrane (CM) progressive representation in the embryo of the monochorionic membrane showed no distinct partitioning or membrane between the twins as the embryos were contained within a single gestational sac. The CM in the monochrionic twin becomes more thickened and stable as development proceeds as shown in Figure 1 and Figure 2. It also shows a characteristic T-sign point of 
insertion in the $25^{\text {th }}$ week of gestation as shown with arrow in Figure 2.

The CM in the dichorionic twin showed distinct partitioning dividing the gestational sac into two compartments. The CM became less thickened and stable as it proceeds in development. The dichorionic twins present a "lambda $(\lambda)$ sign" which is a wedge-shaped protrusion into the inter-twin space, creating a rather curved junction which was evident in the $25^{\text {th }}$ week of development as shown in Figure 4.

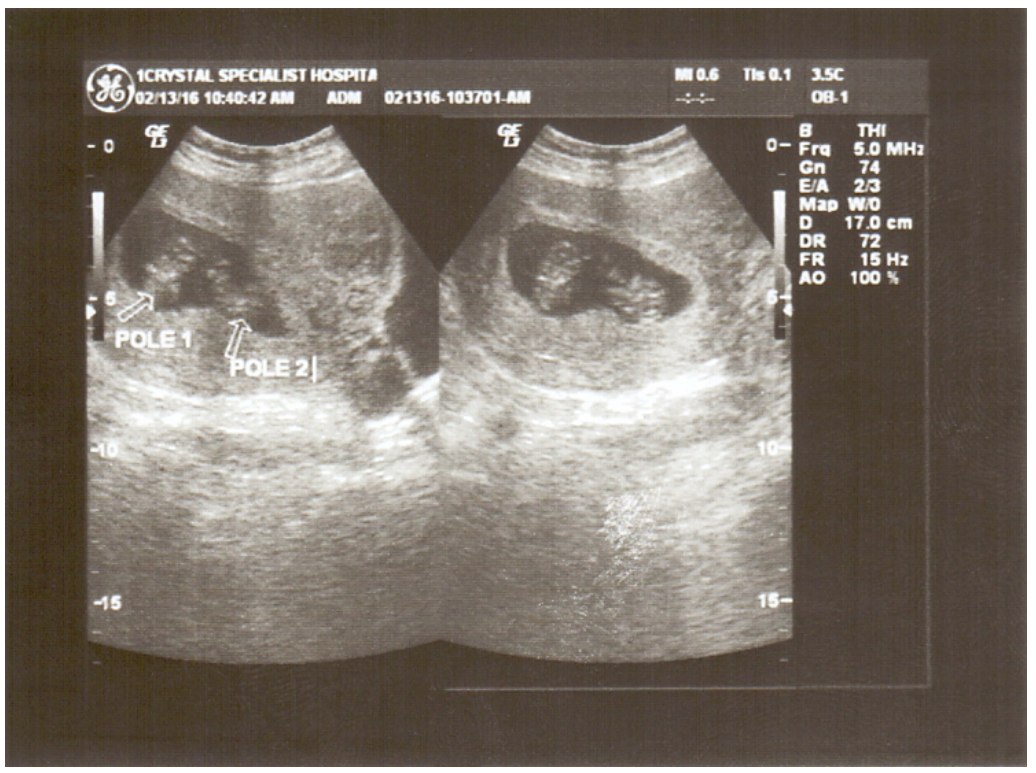

Figure 1. Frozen sonogram of monochorionic monoamniotic twins at 8 weeks gestational age. The two (white) arrows point to the two fetuses in unstable orientation. Observe the (live) "suspended" fetal poles [1] [2] in the sonogram as opposed to "sunken" in non-viable cases.

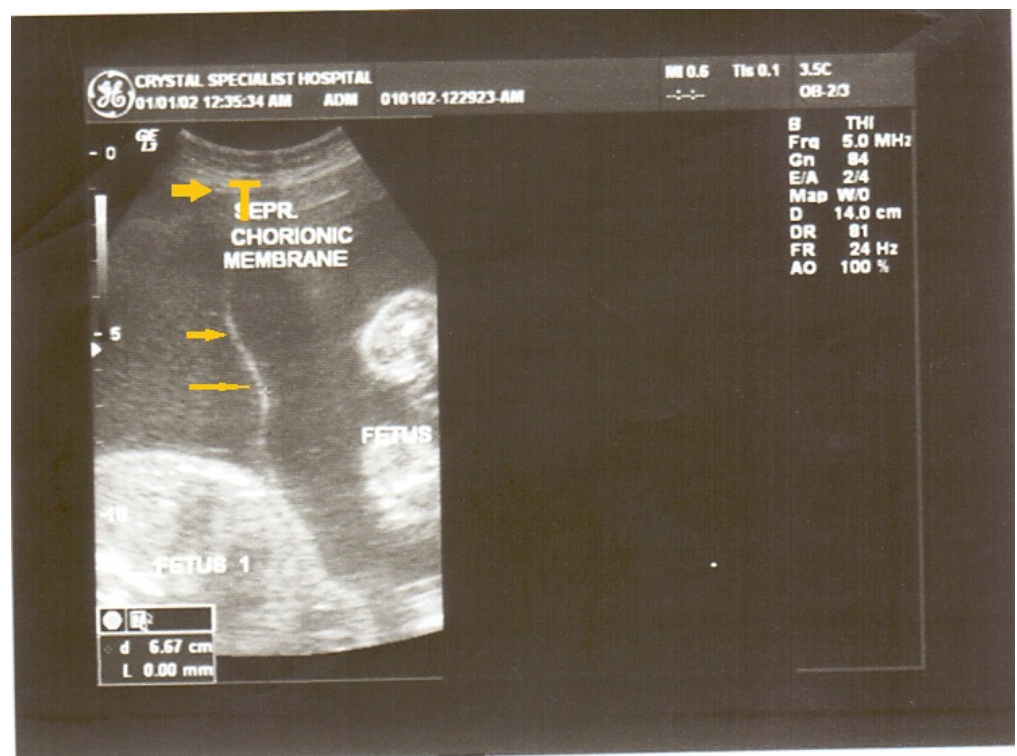

Figure 2. Transverse sonographic image of proximal view thin chorionic membrane in monochorionic diamniotic twin pregnancy at 25 weeks, observe the (T) sign arrowed. 


\section{Discussion}

The determination of chorionicity in multiple gestations is one that confounds many in the medical field. Therefore, adequate highlighted evidence of sonographic vision of the growth pattern and modification of chorion membrane during development is important as it is used to determine an abnormality in growth pattern. Chorionicity is most reliably established by sonographic assessment early in gestation hence it provides on-time discovery of abnormalities in twin gestations. Early detection of abnormalities can lead to appropriate treatment which can improve perinatal outcomes [10].

The present study showed that chorionic membrane bounded the gestational sac in the monochorionic twin and this was modified by becoming more thickened from the $8^{\text {th }}-25^{\text {th }}$ week of development which is evident in the sonographic view. This may be due to increased proliferation of syncytiotrophoblasts during development which creates the evident thickness over time. More so, there is physical transformation of the chorionic membrane to form a T-shape point of insertion. In the dichorionic twins, the membrane forms a partition thus separating the twins and housing each in a separate sac. The dichorionic membrane expressed lesser thickened morphology from the $8^{\text {th }}-25^{\text {th }}$ week of gestation. Additionally, the dichorionic membrane undergoes progressive loss of thickness to produce a characteristic feature of the lambda sign (Figure 3 and Figure 4) also called the "Twin Peak" sign. By the $25^{\text {th }}$ week of gestation, it may be used as a characteristic tool to deduce abnormalities in progression. The sign has since been described by Bessis and Papernik in the 1980s and referred to as the triangular tissue projection extending from the base of the chorion membrane in dichorionic pregnancies with a single fused placenta [11]. This sign is exclusive in

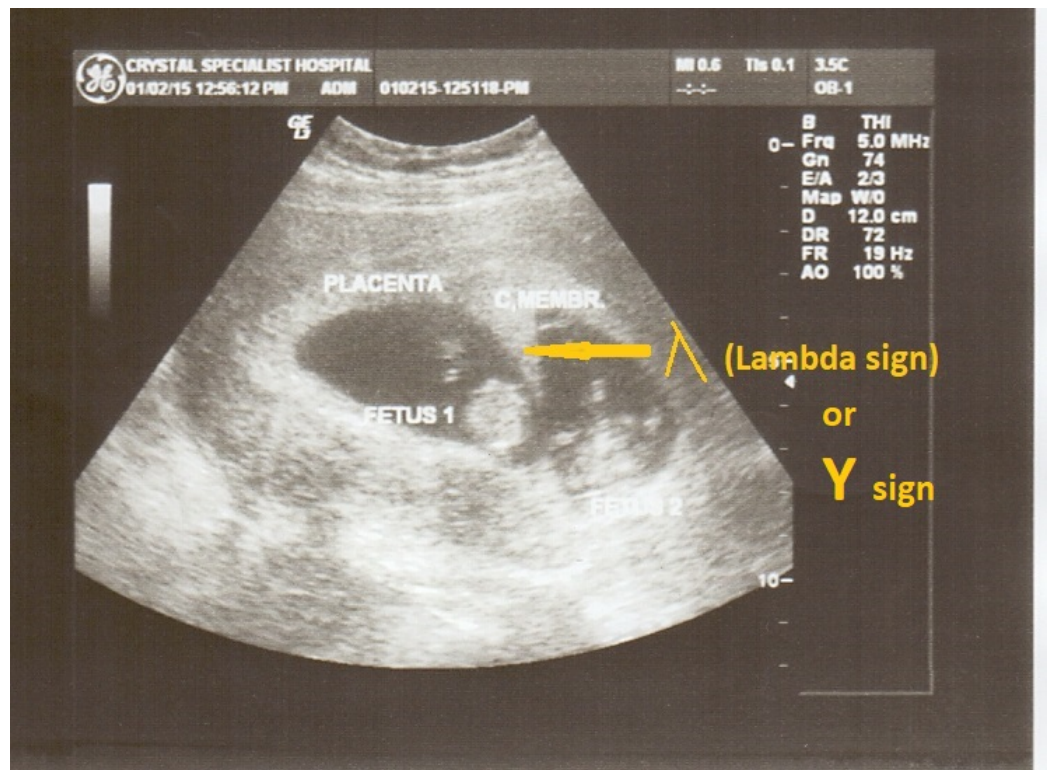

Figure 3. Showing ultrasound image of thick chorionic membrane (CM) in dichorionic diamniotic twins at 8 weeks. Note the triangular projection $\mathrm{CM}$ emanating from fused bi-placentas. 


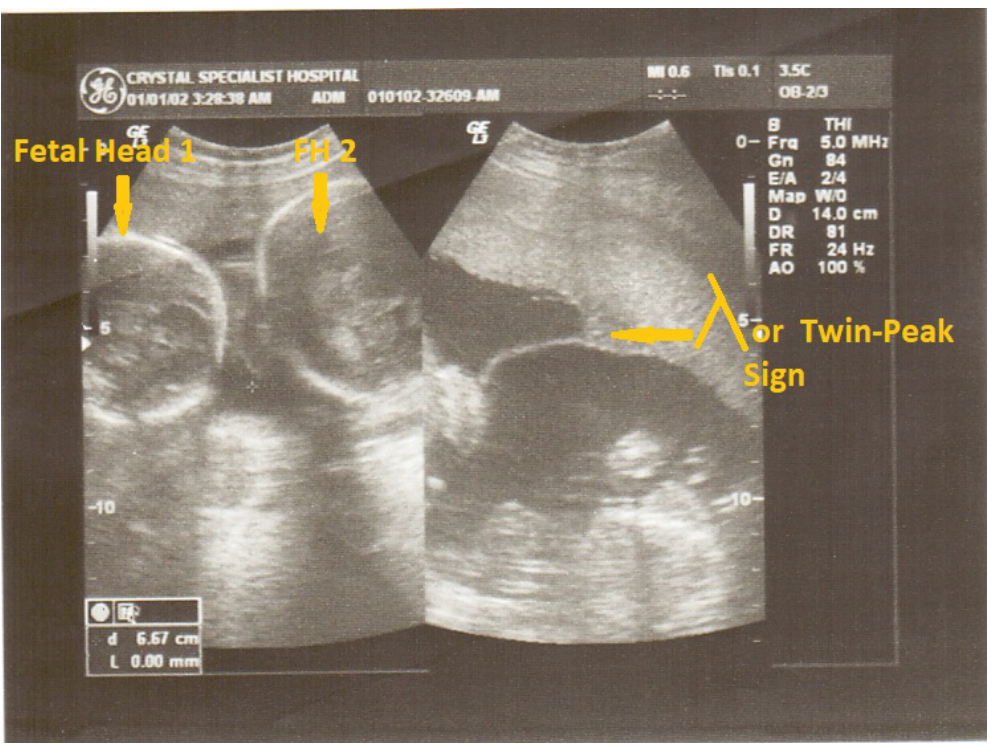

Figure 4. Transverse ultrasound image of chorionic membrane in dichorionic diamniotic twins at 25 weeks gestational age. Note the lambda $(\lambda) /(\mathrm{Y}) /$ Twin-Peak-Sign arrowed.

twin dichorionicity and important for safer monitoring of its development and progression [12]. In conclusion, the accuracy of ultrasound in the assessment of chorionicity in the first trimester is high and is mainly based on the observation of lambda and T-sign. Different sonographic signs such as the characteristics of the inter-twin membrane and a typical T-shaped or lambda appearance in monochorionic and dichorionic pregnancy respectively may be used to evaluate chorionicity [13] [14]. More so, several studies have confirmed the accuracy of these signs in predicting chorionicity [15] [16] [17] [18].

\section{Conclusion and Recommendations}

The determination of chorionicity during gestation is the first step for an accurate management of twin pregnancy. Knowledge of chorionicity helps in risk assessment, genetic counseling, invasive procedure and management of some abnormalities. It is best done in the first trimester and monitored progressively. It is recommended that sonographic assessment of developmental process of chorion membrane should be carried out to provide direct access implementation for better understanding, improved learning process and to add to the body of in-utero medical literature and knowledge. More importantly, if the knowledge of the development of chorion membrane is adequate, abnormalities could be projected early and solutions will be provided accordingly.

\section{Conflicts of Interest}

There are no conflicts of interest.

\section{References}

[1] Michael, R. (2000) Human Heredity Principles and Issues. Cummings, 104. 
[2] Cordero, L., Franco, A., Joy, S.D. and O'shaughnessy, R.W. (2005) Monochorionic Diamniotic Infants without Twin-to-Twin Transfusion Syndrome. Journal of Perinatology, 25, 753-758. https://doi.org/10.1038/sj.jp.7211405

[3] Shulman, L.S., van, V. and John, M.G. (2006) Prenatal Medicine. Taylor \& Francis, Washington, DC, 447.

[4] Sperling, L. and Tabor, A. (2001) Twin Pregnancy: The Role of Ultrasound in Management. Acta Obstetricia et Gynecologica Scandinavica, 80, 287-299. https://doi.org/10.1034/j.1600-0412.2001.080004287.x

[5] Allen, V.M., Windrim, R., Barrett, J. and Ohlsson, A. (2001) Management of Monoamniotic Twin Pregnancies: A Case Series and Systematic Review of the Literature. BJOG, 108, 931-936. https://doi.org/10.1111/j.1471-0528.2001.00216.x

[6] DeFalco, L.M., Sciscione, A.C., Megerian, G., Tolosa, J., Macones, G., O’Shea, A., et al. (2006) Inpatient versus Outpatient Management of Monoamniotic Twins and Outcomes. American Journal of Perinatology, 23, 205-211. https://doi.org/10.1055/s-2006-934091

[7] Heyborne, K.D., Porreco, R.P., Garite, T.J., Phair, K. and Abril, D. (2005) Improved Perinatal Survival of Monoamniotic Twins with Intensive Inpatient Monitoring. American Journal of Obstetrics Gynecology, 192, 96-101. https://doi.org/10.1016/j.ajog.2004.06.037

[8] Wilting, J., Neeff, H. and Christ, B. (1999) Embryonic Lymphangiogenesis. Cell and Tissue Research, 297, 1-11. https://doi.org/10.1007/s004410051328

[9] Cimpean, A.M., Ribatti, D. and Raica, M. (2008) The Chick Embryo Chorioallantoic Membrane as a Model to Study Tumor Metastasis. Angiogenesis, 11, 311-319. https://doi.org/10.1007/s10456-008-9117-1

[10] Huber, A., Diehl, W., Bregenzer, T., Hackelöer, B.J. and Hecher, K. (2006) Stage-Related Outcome in Twin-Twin Transfusion Syndrome Treated by Fetoscopic Laser Coagulation. Obstetrics \& Gynecology, 108, 333-337. https://doi.org/10.1097/01.AOG.0000225945.17022.6b

[11] Bessis, R. and Papernik, E. (1981) Echographic Imagery of Amniotic Membranes in Twin Pregnancies. Twin Research 3: Twin Biology and Multiple Pregnancy. Alan R Liss, New York, 183-187.

[12] Dias, T., Arcangeli, T., Bhide, A., Napolitano, R., Mahsud-dornan, S. and Thilaganathan, B. (2011) First-Trimester Ultrasound Determination of Chorionicity in Twin Pregnancy. Ultrasound in Obstetrics \& Gynecology, 38, 530-532. https://doi.org/10.1002/uog.8956

[13] Stenhouse, E., Hardwick, B., Maharaj, S., Webb, J., Kelly, T. and Mackenzie, F.M. (2002) Chorionicity Determination in Twin Pregnancies: How Accurate Are We. Ultrasound in Obstetrics \& Gynecology, 19, 350-352. https://doi.org/10.1046/j.1469-0705.2002.00679.x

[14] Carroll, S.G., Soothill, P.W., Abdel-Fattah, S.A., Porter, H. and Montague, I. (2002) Kyle PM Prediction of Chorionicity in Twin Pregnancies at 10-14 Weeks of Gestation. BJOG, 109, 182-186.

[15] Menon, D.K. (2005) A Retrospective Study of the Accuracy of Sonographic Chorionicity Determination in Twin Pregnancies. Twin Research and Human Genetics, 8 , 259-261. https://doi.org/10.1375/twin.8.3.259

[16] Lee, Y.M., Cleary-Goldman, J., Thaker, H.M. and Simpson, L.L. (2006) Antenatal Sonographic Prediction of Twin Chorionicity. American Journal of Obstetrics and Gynecology, 195, 863-867. https://doi.org/10.1016/j.ajog.2006.06.039 
[17] Afodun, A.M., Ayinde, T.O., Quadri, K.K. and Masud, M.A. (2015) Concise Human Chorionic Atlas (Ultrasound, Gross, Histopathologic and Eponymical Approach). Xlibris Publishers, 50 p. https://www.xlibris.com/Bookstore/BookDetail.aspx?BookId=SKU-001001968

[18] Finberg, H.J. (1992) The “Twin Peak" Sign: Reliable Evidence of Dichorionic Twinning. Journal of Ultrasound in Medicine, 11, 571-577.

https://doi.org/10.7863/jum.1992.11.11.571 